\title{
The Innovation Agenda: Potential Implications for the Engineering Design Curriculum
}

\author{
Antony J. Hodgson and H.F. Machiel Van der Loos \\ Department of Mechanical Engineering, University of British Columbia \\ ahodgson@mech.ubc.ca
}

\begin{abstract}
The phrase "Innovation Agenda" is being widely used these days to describe a broadly perceived problem in Canada - namely, that the nation as a whole may be lagging our peers around the world, despite having a highly educated workforce and various other favourable conditions. The bulk of the public discussion about innovation is taking place in organizations and venues that connect business and government; engineering as a discipline is notably absent in these discussions. The purpose of this presentation is to describe recent public reports and analyses related to innovation and to prompt a discussion of how engineers might participate more visibly in these processes and what implications there might be for curriculum design.
\end{abstract}

Keywords: Innovation, design curriculum, design process

\section{INTRODUCTION}

In recent years, a number of influential reports have been issued discussing the state of innovation in Canada. Some of the most notable of these reports are "Review of Federal Support to Research and Development" (Jenkins Report, 2011), "Innovation Report Card" (Conference Board of Canada, 2012) and the OECD Science, Technology and Innovation Outlook (2012).

The overall assessment from these reports is that, while Canada performs well in research, and has both a highly trained workforce and other advantages [1], it is a relative underperformer amongst the OECD countries in translating research findings into commercialized products and systems. Many of the underlying factors are business related, and so the majority of the participants in these innovation-related deliberations are drawn from the business community. In our view, engineers as a formal, organized group are strikingly absent. The purpose of this paper and associated presentation is to raise the issues of how engineers might play a larger role in public discussions and how we might modify our curriculum.

\section{REPORT FINDINGS}

Some key findings of the 2012 OECD Science, Technology and Industry Outlook for Canada include: an above average science base, below average industrybased R\&D investments, average availability of venture capital, below average number of startups, average capability in knowledge translation activities (though with significantly higher international cooperation ratings), and very high participation in tertiary level education. The single biggest public policy difference between Canada and our OECD peers is our overwhelming reliance on indirect funding for business-related R\&D (SR\&ED tax rebates), vs. markedly more targeted funding elsewhere.

\section{DISCUSSION}

To date, the bulk of the public discussion about innovation has focused on structural (eg, taxation, education, infrastructure, etc) and business issues, in which business leaders and academics are prominently involved. To the extent that technology is seen to be linked to innovation, there appears to be a presumption that this is largely an internal company matter. Given that innovation typically requires mutual contributions from technical and business people, there appears to us to be a significant opportunity for engineering professional bodies and academics across the country to play a larger role in these important public discussions.

A key recommendation of the 2012 Conference Board of Canada report on innovation was that Canada develop coordinated policies around targeted industrial areas with high global market potential. Since innovation is critically dependent on technological capacity, we believe that engineers should be explicitly introduced to the concept of innovation as a public goal requiring input from and coordination between both the public and private sectors. In particular, engineers should be taught to view innovation as a process involving technologicallycompetent professionals (including university-based researchers), business and industry, and government programs and policy. While some of these issues may be addressed in business or entrepreneurship-type courses, we would argue that addressing the framework of innovation would be most appropriate in the context of our engineering design curriculum.

\section{References}

[1] Pilat D (2005) Canada's Productivity Performance in International Perspective, International Productivity Monitor, Centre for the Study of Living Standards, 10:24-44 